\title{
ONTOLOGICAL GROUNDING OF A KNOWLEDGE MAPPING METHODOLOGY: DEFINING DATA, INFORMATION, AND KNOWLEDGE
}

\author{
Robert Joseph Skovira, Robert Morris University, skovira@rmu.edu
}

\begin{abstract}
The paper presents an articulated conceptualization of four major categories of knowledge management. The categories are ontology, data, information, and knowledge. These categories make up a meta ontology as a ground for a knowledge mapping methodology. The paper discusses each category and gives a brief taxonomy of each.
\end{abstract}

Keywords: Knowledge map, Ontology, Data, Information, Knowledge, Knowledge management.

\section{INTRODUCTION}

Unwittingly, Ephrein Chambers who in the early 1700s "had called his Cyclopedia 'a map of knowledge'”[11] began a trend. What do you need to know to do your job? What knowledge is of use to you? Where can you find this knowledge? Whom do you ask? Is there an expert to go to in order to find out the information you require? Are there repositories of 'best' practices or solutions to problems which you can access? How does knowledge show up in the sociocultural environment of the corporation? These are some of the questions that people ask of themselves and others. These questions lead into the world of knowledge management and to a practical method of obtaining personal knowledge.

Articulating anything one "knows" involves expressing in some manner, words, pictures, actions, the "anything." The problem is representing in some symbolic form, if one and one's culture have the symbolic forms, anything known unconsciously, subconsciously, or tacitly, as something known consciously and explicitly, or reflectively and articulatively. This is the "tacit turn." To express the silent side of what we know is a difficult chore. The task is made easier if we actually do have a lot of stuff buried and silent - Ortega y Gasset's [42] soil and subsoil, culturally contexturalizing knowledge which one brings to any situation, and a culture and language which is expressive.

\section{Knowledge Management}

Knowledge management is about the presence and use of knowledge in the operations of a firm to increase productive activities and ultimately profits by maintaining competitive advantage in the market
[33; 39; 59]. An assumption is that the knowledge needed to manage a business resides in the organization's formalized procedures and documents and its people. The structures of an organization constitutes a taxonomy of knowledge of how to do business; they are "knowledge in the world" [40; 45].

Organizational knowledge provides what people need to know in order to do their everyday jobs[54]. Knowledge management advocates assume that a firm's knowledge is represented in the corporation's best practices [5; 24]. These are knowledge of how to do things ; they show up in an architecture of performative knowledge [40]. As Bukowitz and Williams [8] write "Knowledge management is the process by which the organization generates wealth from its knowledge or intellectual capital” (p.2). This also allows for knowledge sharing [3; 26] across what communities of practice. Knowledge management theory suggests that employees, knowledge workers [19] share a common body of knowledge and a common framework for using the knowledge. They share a common vocabulary, and common views of the tools they use, the projects they work on, and of the corporate mission and vision. Knowledge management theory further suggests that knowledge workers work within common semantic or knowledge spaces. Knowledge or semantic fields are localized in communities of practice or local social networks. Knowledge is shared as the commonsense of communities of practice [18; 24 ; 47].

\section{Knowledge Mapping}

The problem for practitioners of knowledge management is mapping personal habits and models of knowing to organizational situations and their circumstances [12; 13; 14; 49; 52; 58]. Bergeron [5] writes that knowledge mapping is "[a] process of identifying who knows what, how the information is stored in the organization, where it's stored, and how the stores of information are interrelated" (p. 49). Knowledge mapping is matching personal ontologies and organizational ontologies [12].

The problem for knowledge management practitioners is exacerbated by the fact that organizations are infoscapes [31; 51], or knowledge ecologies [6; 13; 48; 58]. Organizations are topographies of communities of practice [5]. People 
live and work within personal and social "webs of significance" [25]. They are high and low contexts of knowing and informing [29], where knowledge moves and is used according to the social and political terrain [6]. Taking these things into account, creating a knowledge map is articulating relationships between personal habits of informing, or knowledge sharing, and knowing that, what, and why, and organizational habits of knowing, in-place structures and procedures of embedded commonsense [8; 53]. This process and endeavor assumes people know what they mean by such terms as "data," "information," "knowledge," whether tacit, implicit, and explicit, and "ontology," as well as by the terms "community of practice," and "knowledge life cycle:" processes of acquiring, discovering, representing, sharing, and transferring of knowledge [5; 30; 56]. There are common definitions and concrete examples of these categories of experience ready-to-hand.

Knowledge management theorists are also faced with the problem of formally representing what people know. There are different forms of "codifying" what is called "data," "information," or "knowledge", of dealing with fixed and systematic regularities [6; 16; 17]. Documents and recorded narratives may be some of the ways of ascertaining the "fixities" of knowing [6] organizationally. Descriptive observations and analysis of knowledge domains [54] may be ways of attaining the personal side of knowing and informing.

\section{A Knowledge Map Example}

What people know, and use as knowledge, are the consequences of the affordances and constraints of shared systems of meanings. Shared systems of meanings are ontologies. Ontologies are what people know in their situations. These are habits of action and language, styles of doing things and saying things, models of thinking and feeling about situations, interactive and transactional states of affairs. Knowledge maps represent ontological terrains.

There are many ways to map knowledge, to present information about what and how people do and say things in situations in organizations. When thinking about knowledge mapping, we are thinking about the logic of at least two different information spaces, fields [16; 31], interacting infoscapes [51], personal and organizational, constituting a situation. On the one hand, we have the situation engaged in, and on the other hand the results or products of the persons engaged in the situation. Personal descriptions of a situation engaged in are descriptions of language used, decisions made, and actions taken. A personal description is a person's "take" on a situation. A personal "take" on a situation is a descriptive observation, a narration or story [6]. The observations are descriptions of "knowledge" in play. These descriptions are "data' used to create "information" about situated events and happenings, contexts of knowledge use. Situations engaged in are present in agenda, decisions-to-be-made, actions-to-be-taken, and documents as evidence for decisions and actions.

A knowledge map is a summary that relates personal experience to an organizational situation. It may relate the results of experience in the forms of documents, or artifacts, or descriptive observations. Elements of knowledge maps become signs of ideas and situations, relationships and processes. Elements of knowledge maps indicate documents and artifacts, situations, and personal "takes", descriptive observations. Knowledge maps are ordered arrangements, logical perspectives of on-the-ground things and states of affairs. An partial example of a possible knowledge map follows; space does not allow other forms of other types of knowledge maps.

1. IRB meeting Weds $1 \mathrm{pm}$

1.1. IRB purpose is to evaluate research proposals in terms of possible harm to the participants in the research.

1.2. Research proposal form (organizational)

1.3. IRB check list for evaluating research proposals (organizational)

1.4. IRB policy statements document (organizational)

1.5. IRB members list (organizational)

1.6. IRB meeting agenda (organizational)

1.6.1. IRB minutes (organizational)

1.7. IRB research proposal (personal)

1.7.1. IRB meeting: descriptive observation (personal)

1.7.1.1. The IRB met from $1 p$ to 230p on Weds. We evaluated a research proposal which required a full review. We also worked on the IRB proposal review checklist and made changes. As co chair, with J. C co chair \& F. K chair, agreed to a meeting on Tues to work on IRB policy statements.

\section{The Problem}

This paper's problem is an articulation of these shareable definitions of "data," "information," and "knowledge," or a conceptualization of a meta ontology which will serve as the ground of a knowledge mapping methodology and, consequently, for successfully doing a knowledge map. 
The paper discusses four meta categories of knowledge management and of any attempt at doing a knowledge map. Those four categories are the conceptions of ontology, data, information, and knowledge. The paper first discusses the category and then presents a taxonomy.

\section{ONTOLOGY}

An ontology is an articulation of the "Whats", concepts or mental models and objects or things, which make up a worldview. An ontology is a set of personal and organizational shared systems of meanings and shared things which are meaningful. Castel [10] writes "Ontology is the way we carve up reality in order to understand and process it. Information, still a vague and misunderstood concept, is the product of that carving” (p. 29). Personal ontologies are things and their meanings which a person uses in everyday activities. These meaningful things, their use is part of their meaning, are taken for granted and are always there for the person. They are habitual ways of saying and doing things. They are fundamental to any communication [22; 28]. They are the mental models, "knowledge in the head," which are a person's habitual way or style of doing and saying things $[12 ; 27 ; 30 ; 40 ; 41]$. They are how we know what we know. These mental models are conceptions or ideas of affairs and states of affairs. An ontology is a "conceptualization" of a world [27]. An ontology is a system of concepts framing a view or perspective.

These concepts guide a person's thinking and action, and a person's communicative acts. They are people's decision making models: how to judge something, action models: how to do something, and even system models: how things work, how the organization works [40]. There many other models or conceptions. As Lakoff and Johnson [32] write: “Our concepts structure what we perceive, how we get around in the world, and how we relate to other people. Our conceptual system thus plays a central role in defining our everyday realities. If we are right in suggesting that our conceptual system is largely metaphorical, then the way we think, what we experience, and what we do every day is very much a matter of metaphor.” (p. 3). These metaphorical conceptual systems show up in stories and antidotes [6] about events in which people have been involved, and they represent intentions pursued, things done, and consequences suffered.

Organizational ontologies consist of shared systems of things and meanings which facilitate action and communication. Organizational ontologies are articulated conceptual sets of objects and their relationships which are used situationally within a business to represent structures and procedures [22; 28]. They are shareable repositories of collected common knowledge or organizational models of things. The modeled objects and their relationships are the products and services of a firm $[2 ; 21 ; 30]$. "An explicit conceptualization model, comprised of objects, their definitions, and relationships among the objects is called an ontology...”[2, p. 13-7].

\section{A Taxonomy for “Ontology”}

1. Worldview
1.1. Action
1.2. Communication
1.3. Situations

2. Personal

2.1. Systems of meanings

2.2. Metaphors and stories

2.3. Mental models

2.4. Objects or things

2.5. Relationships

2.6. Habits

3. Organizational

3.1. Shared systems of meaning

3.2. Shared situations \& things

3.3. Metaphors and stories

3.4. Objects

3.5. Relationships

3.6. Structure and procedures

\section{DATA}

Although data is a term used in knowledge management theory, its conceptualization remains fuzzy. The discussion has a long history. It is a "godword” [9; 57] for many people. The term's genealogy has it being used rhetorically as a boundary marker for being "scientific' or "objective." Simply, the word "data" means the "Givens", literally "thosethings-having-been-given.” Usually, data are defined as raw and meaningless facts, although it is hard to understand facts as meaningless. Some describe data as the givens of a situation, being symbolic (signs) in nature and a part of experience. Roberts [46] writes that "Data means anything that can be observed, read, or heard by another...” (p. 245), while Bergeron [5] writes that "Data are numbers. They are numerical quantities or other attributes derived from observation, experiment, or calculation” (p. 10). Data are viewed as disorganized facts which need to be processed and dealt with in an orderly fashion. They are, however, discrete facts, descriptive of the event world which surrounds any system [56]. As descriptions they are observations about the world and those things, objects and relationships, which are potentially useful [1; 13; 14; 37]. Davenport and Prusak [14] write "Data is a set of discrete, objective facts about events. In an organizational context, data 
is most usefully described as structured records of transactions" (p. 2).

\section{A Taxonomy for "Data"}

1. The Givens

1.1. Events

1.2. Activities

1.3. Objects

1.4. Relationships

2. Facts

2.1. Unorganized

2.2. Unstructured

2.3. Meaningless

2.4. Irrelevant

2.5. Objective

2.6. Discrete

3. Observations

3.1. Descriptive

3.2. useful

3.3. Transactional

3.4. Structured

4. Symbols

4.1. Experience

4.2. Descriptions

\section{INFORMATION}

As one of the "god-words" for knowledge management, the term "information" has a long genealogy. Information science $[4 ; 7 ; 15 ; 35 ; 38 ; 50]$ is a discipline built around the idea of information. Many people have expended much energy trying to clarify the concept. Information is a represented abstract entity [16; 17; 50]. Davenport [13] thinks that the word is a cover term including both data and knowledge. But, nevertheless, there is always a differentiation. Information is usually considered to be about how something, "data," is useful and meaningful. Davenport and Prusak [14] write that information is "...is data that makes a difference” (p. 3). Information provides contexts for understanding states of affairs. Information is useful or has value when applied situationally [58]. It is analyzed data aimed at some objective or task. Analyzed data simply means that data has been formed into a structured and meaningful set of facts. Information is the organized set of details about some object or situation [5; 56]. "Information has been defined as data that is 'in formation' - that is, data that has been sorted, analyzed, and displayed, and is communicated through spoken language, graphic displays, or numeric tables” [18, p. 13]. Information is aimed at accomplishing objectives and tasks. It has a purpose in business situations. And to be purposeful, information has to be relevant, timely, accurate, and with sufficient scope and reach $[1 ; 13 ; 14 ; 31 ; 37]$. Information is the content of knowledge [17]. Some view information to be propositional in nature, that an informing statement tells us something in the world [16; 17; 23]. Devlin [17] writes that "...information always takes the form of a statement that some object is of some type" (p. 61). Information is a conception. "[Information] is the model we create of the world - in all its representational complexity. It is the model we ascribe to in computing; the structure we create in order to make sense of the world and communicate among ourselves" [10, p. 29].

\section{A Taxonomy for "Information"}

1. Data

1.1. Difference

1.2. Details

1.3. Representation

2. Meaning

2.1. Abstraction

2.2. Situations

2.3. Structure

2.4. Usefulness

2.5. Relevant value

3. Purpose

3.1. Contextual and situational

3.2. Ends-in-view

3.3. Timeliness

3.4. Accuracy

3.5. Scope

4. Knowledge

4.1. Content

4.2. Proposition

5. Concept

5.1. Proposition

\section{KNOWLEDGE}

It is like trying to hit jello with a hammer. "Knowledge" is another divine term. Knowledge is a difficult semantic object or concept. Knowledge is about our understanding of things in the world, including our organizational worlds [59]. Knowledge enhances experience [5]. Experience is a result of what the individual knows; an individual experiences only what he or she knows [1;41]. Knowledge is uniquely human because it is about the meanings of things for the individual even as the individual is part of situations within organizations or social groups [1; $6 ; 44]$. The questions what do you know and how do you know (it) have probably been around for all of human history. Plato and Aristotle began an intellectual tradition which still has not run its course. Knowledge, knowing, is the use of shared systems of meanings, via their signs, to interpret, understand, and act upon stuff-in-the-world, i.e., things, conversations, actions, events, situations, and circumstances [2]. 
Although they tend to ignore it, knowledge management theorists, in order to talk about its management or its mapping, must settle the conceptualization of what knowledge is [12]. Genealogically speaking, Davenport and Prusak [14] give a seminal conceptualization: "Knowledge is a fluid mix of framed experience, values, contextual information, and expert insight that provides a framework for evaluating and incorporating new experiences and information. It originates and is applied in the minds of knowers. In organizations, it often becomes embedded not only in documents or repositories but also in organizational routines, processes, practices, and norms” ( p. 5). Unpacking this conception of "knowledge" must be done in other venues because of space.

Knowledge is something "in the head" [40; 41] consisting of mental models and their relationships in terms of possible use in situations (declarative and procedural knowledge); they are systematic confections that habitually handle the stuff of human activity [2; 16; 18; 25; 58]. Knowledge is "[v]aluable information from the human mind [and][i]ncludes reflection, synthesis, [and] context..." [13, p. 9]. Knowledge management theorists sometimes divide the concept up into three parts: tacit, implicit, and explicit knowledge. They make further subdivisions into knowledge how, knowledge that, and even knowledge why.

Tacit knowledge is silent and habitual systems of knowing which are unconscious (subconscious), and which one is aware of indirectly [4; $20 ; 39 ; 43 ; 55]$. Tacit knowledge is the personal taken-for-granted frames and models which people use to perceive and think about, and act in, everyday situations [8; 56]. People do not think about most of the things they do and say, they simply do and say them. Because individuals have spent much time acquiring our silent mental models and frames, and because they have lived with them in place for some time, these models and frames are difficult to recognize and to represent in a way which is reusable $[1 ; 5]$. They "run silent and deep" in individuals' daily lives. These silent habits of knowing configure everything naturally in meaningful ways.

Implicit knowledge is synonymous with tacit knowledge in many ways. Implicit knowledge is a state of affairs between tacit and explicit ways of knowing things. Knowledge implicitly shows up in everyday unspoken and unwritten policies and procedures which are in-use or rules-of-the-game, embedded in situations. Policies in-use and procedures in-use are mental models put into play because they are the usual, traditional, modes of doing things. They are rules-of-the-game developed experientially over time. For a person newly hired, they are folded into the everyday organizational events and activities as a source of learning expertise $[1 ; 6 ; 39 ; 58]$. Such ways of knowing how to do things and handle problematic states of affairs are wedded to one's situational expertise. In most interactions, implicit knowledge is knowledge derived from expertise [1]. As Bergeron [5] writes "Implicit knowledge, like tacit knowledge, typically is controlled by experts. However, unlike tacit knowledge, implicit knowledge can be extracted from the expert - through a process termed knowledge engineering” (p. 18).

Explicit knowledge, on the other hand, is knowledge in the world, written and verbal [5; 40], articulated and expressed in documents, organizational hierarchies and relationships, processes and procedures, stories told about problem solutions and experience of states of affairs. Explicit knowledge is expressed conceptions $[1 ; 2 ; 6 ; 8]$. “...explicit knowledge is knowledge codified and digitized in books, documents, reports, white papers, spreadsheets, memos, training courses, and the like" [1, p. 47; 56]. Articulated knowledge is statements about circumstances, situations, actions and their consequences [17; 23]. Explicit knowledge is the representation of common sensibilities [18] or shared meanings [25] in formal and physical things, even the physical layout of buildings and places to work. Explicit knowledge is the social and organizational expression of silent and personal habits of know how, know that, and know why [56]. "Knowledge is a social construction. It is developed and certified within social institutions.” [36, p. 240].

\section{A Taxonomy for "Knowledge"}

1. Understanding

2. Framed experience

2.1. Values

2.2. Information

2.3. Expertise

2.4. Evaluation

3. In the head

3.1. Mental models

3.2. Habits

4. Tacit

4.1. Unconscious

4.2. Subconscious

5. In the world

6. Implicit

6.1. Expertise

7. Explicit

7.1. Expressed conceptions

7.2. Documents 
7.3. Stories

7.4. $\quad$ Procedures

8. Social

8.1. Organizational structures

8.2. Physical layouts

\section{CONCLUSION}

The paper presented an articulated conceptualization of four major categories of knowledge management. The categories are ontology, data, information, and knowledge. An ontology is an articulated conceptualization of a set of assertions about one's world. Data are the selected grounds for inquiry into one's assertions or conceptions. Information is a conception or assertion about one's world. Knowledge is a warranted, grounded, assertion or conception within a conceptualization. These categories make up a meta ontology as a ground for a knowledge mapping methodology. The paper discussed each category and gave a brief taxonomy of each category.

\section{REFERENCES}

1. Awad, E. M. \& Ghazini, H. M. (2004). Knowledge Management. Upper Saddle River, NJ: Pearson Education Prentice Hall.

2. Becker, G. (1999). Knowledge discovery. In J. Liebowitz (ed.), Knowledge management handbook (pp. 13-1--13-17). Boca Raton, FL: CRC Press LLC.

3. Bednar, C. (1999) Capturing and packaging knowledge. In Cortada, J. W. and Woods, J. A. (Eds.), The knowledge management yearbook 1999-2000 (pp. 211-220). Boston: ButterworthHeinemann.

4. Belkin, N. J. \& Robertson, S. E. (1976, JulyAugust). Information science and the phenomenon of information. Journal of the American Society for Information Science 27(4), 197-204.

5. Bergeron, B. (2003). Essentials of knowledge management. Hoboken, NJ: Wiley \& Sons.

6. Brown, J. S. \& Duguid, P. (2000). The social life of information. Boston, MA: Harvard Business School Press.

7. Buckland, M. (1991). Information and information systems. Westport, CN London: Praeger.

8. Bukowitz, W. R. \& Williams, R. L. (2000). The knowledge management fieldbook. London: Pearson Education.

9. Burke, K. (1970). The rhetoric of religion: Studies in logology. Berkeley: University of California Press.
10. Castel, F. (2002, February). Ontological computing. Communications of the ACM, 45(2), 29-30.

11. Chaplin, J. E. (2006). The first scientific American: Benjamin Franklin and the pursuit of genius. New York: basic Books.

12. Correa da Silva, F. S. \& Agusti-Cullell, J. (2003). Knowledge coordination. West Sussex, England: Wiley \& Sons.

13. Davenport, T. H. (with Prusak, L.). (1997). Information ecology: Mastering the information and knowledge environment. New York Oxford: Oxford University Press.

14. Davenport, T. H. \& Prusak, L. (2000). Working knowledge: how organizations manage what they know. Boston MA: Harvard Business School Press.

15. Debons, A., Horne, E., \& Cronenweth, S. (1989). Information science: An integrated view. Boston, MA: G. K. Hall.

16. Devlin, K. (1999). InfoSense: Turning information into knowledge. New York: Freeman.

17. Devlin, K. (2000). Logic and information. Cambridge: Cambridge University Press.

18. Dixon, N. M. (2000). Common knowledge: How companies thrive by sharing what they know. Boston MA: Harvard Business School Press.

19. Drucker, P. F. (1998). The Coming of the new organization. In Harvard business review on knowledge management. Boston MA: Harvard Business School Press.

20. Durrance, B. (1999). Some explicit thoughts on tacit learning. In J. W. Cortada \& J. A. Woods. (Eds.), The Knowledge Management Yearbook 1999-2000 (pp. 28-36). Boston: ButterworthHeinemann.

21. Edgington, T., Choi, B., Henson, K., Raghu, T. S., \& Vinze, A. (2004, November). Adopting ontology to facilitate knowledge sharing. Communications of the ACM 47(11), 85-95.

22. Fonseca, F. T. \& Martin, J. E. (2005, January 1). Toward an alternative notion of information systems ontologies: Information engineering as a hermeneutical enterprise. Journal of the American Society for Information Science and Technology, 56(1), 46-57.

23. Fox, C.J. (1983). Information and misinformation. Westport, CN: Greenwood.

24. Garvin, D. A. (1998). Building a learning organization. In Harvard business review on knowledge management. Boston: Harvard Business School Press.

25. Geertz, C. (1973). The interpretation of cultures. New York: Basic Books.

26. Gill, P. J. (2001, May). Once upon an enterprise. Knowledge Management, 4 (5), 24-28. 
27. Gruber, T. R. (1993). A translation approach to portable ontologies. Knowledge Acquisition 5(2), 199-220.

28. Gruninger, M. \& Lee, J. (2002, February). Ontology applications and design. Communications of the ACM, 45(2), 39-41.

29. Hall, E. T. (1981). Beyond culture. New York: Achor Books Doubleday.

30. Holsapple, C. W. \& Joshi, K. D. (2004, May). A formal knowledge management ontology: Conduct, activities, resources, and influences. Journal of the American Society for Information Science and Technology 55(7), 593-612.

31. Johnson, J. D. (1996). Information seeking: An organizational dilemma. Westport, CN: Quorum Books.

32. Lakoff, G. \& Johnson, M. (1980). Metaphors we live by. Chicago and London: University of Chicago Press.

33. Liebowitz, J. (2003-2004, Winter). A knowledge management strategy for the Jason organization; A case study. Journal of Computer Information Systems XLIV(2), 1-5.

34. Liu, K. (2000). Semiotics in information systems engineering. Cambridge: Cambridge University Press.

35. Losee, Jr., R. M. (1990). The science of information. New York: Academic Press.

36. March, J. C. (with Heath, C.). (1994). A primer on decision making. New York: The Free Press.

37. Murdick, R. G. with J. C. Munson. (1986). MIS: Concepts and design, $2^{\text {nd }}$ ed. Englewood Cliffs, NJ: Prentice-Hall.

38. Neill, S. D. (1992). Dilemmas in the study of information: Exploring the boundaries of information science. New York: Greenwood Press.

39. Nonaka, I. (1998). The knowledge-creating company. In Harvard Business Review on Knowledge Management. Boston MA: Harvard Business School Press.

40. Norman, D. A. (1988). The design of everyday things. New York: Currency Doubleday.

41. Norretranders, T. (1991/1998). The user illusion: Cutting consciousness down to size. (J. Sydenham, Trans.). New York: Viking.

42. Ortega y Gasset, J. (1967). The origin of philosophy. New York: W. W. Norton.

43. Polanyi, M. (1962). Personal knowledge: Towards a post-critical philosophy. Chicago: University of Chicago Press.

44. Prusak, L. (1999). What's up with knowledge management: A personal view. In J. W. Cortada \& J. A. Woods. (Eds.), The Knowledge
Management Yearbook 1999-2000 (pp. 3-7). Boston: Butterworth-Heinemann.

45. Rapport, M. (2001 July). Unfolding knowledge. Knowledge Management, 4(7), 44-49.

46. Roberts, C. (1999). Can we talk? In J. W. Cortada \& J. A. Woods. (Eds.), The Knowledge Management Yearbook 1999-2000 (pp. 245-253). Boston: Butterworth-Heinemann.

47. Robert-Witt, S. L. (2001, June). Knowledge everywhere. Knowledge Management, 4(6), 3640.

48. Star, S. L. (Ed.). (1996). Ecologies of knowledge: Work and politics in science and technology. Albany, NY: SUNY Press.

49. Skovira, R. J. (2001). The illusive unicorn: a practical method for acquiring, understanding, and using personal knowledge in the organization. CS Online 2001, 14, 31-42.

50. Skovira, R. J. (2002). A conception of information for a postmodernist information science. Kniznicna a Informacna Veda XIX. Bratislava, Slovakia: Filozofickej Fakuty Univerzita Komenskeho.

51. Skovira, R. J. (2004a). Using informational landscape as a model to understand information use and design within organizations. Issues in information Systems, V(1): 308-314.

52. Skovira, R. J. (2004b). Some contrarian marginalia on reading a knowledge management textbook on knowledge. Information Resources Management Association Proceedings..

53. Snowden, D. (1999). A framework for creating a sustainable knowledge management program. In J. W. Cortada \& J. A. Woods. (Eds.), The Knowledge Management Yearbook 1999-2000 (pp. 52-64). Boston: Butterworth-Heinemann.

54. Spradley, J. P. (1980). Participant observation. New York: Wadsworth Thomson Learning.

55. Sverby, K. E. (1999). Tacit knowledge. In J. W. Cortada \& J. A. Woods. (Eds.), The Knowledge Management Yearbook 1999-2000 (pp. 18-27). Boston: Butterworth-Heinemann.

56. Tiwana, A. (2002). The knowledge management toolkit: Orchestrating IT, strategy, and knowledge platforms, (2 $\left.{ }^{\text {nd }} E d.\right)$. Upper Saddle River, NJ: Prentice Hall PTR.

57. Weaver, R. M. (1953). The ethics of rhetoric. South Bend, IN: Gateway Editions.

58. Wiig, K. M. (1999). Introducing knowledge management into the enterprise. In J. Liebowitz (ed.), Knowledge management handbook (pp. 31-3-41). Boca Raton, FL: CRC Press LLC.

59. Zand, D. E. (1981). Information, organization, and power; Effective management in the knowledge society. New York: McGraw-Hill. 